\title{
Recovery of the recurrence interval of Boso slow slip events in Japan
}

\author{
Shinzaburo Ozawa*, Hiroshi Yarai and Tomokazu Kobayashi
}

\begin{abstract}
We present the spatiotemporal evolution of the Boso slow slip event with a moment of $20 \times 10^{18} \mathrm{~N}$ m that occurred in June 2018; such events, which have a duration of 1-2 weeks, have repeatedly occurred off the Boso peninsula, east Japan. The initial rupture of the 2018 event started off central Boso peninsula and the center of the rupture area moved southward over time, as was observed in previous events. The moment and the slip rate of the 2018 event are the largest among the previous Boso slow slip events. The recurrence interval of major Boso slow slip events has changed from 4 to 6 years before the 2011 Tohoku earthquake to intervals of 0.6, 2.2 and then 4.4 years after the Tohoku earthquake. It has taken 7 years for the recurrence interval of the major Boso slow slip events to roughly recover to that before the Tohoku earthquake. The relationship between the cumulative moment and recurrence time indicates a slip-predictable model rather than a time-predictable model before the Tohoku earthquake. If a slip-predictable model holds after the Tohoku earthquake, there was possibly an increase in the moment release rate after the 2011 Tohoku earthquake. Boso slow slip events are changing the stress state in favor of the occurrence of an interplate earthquake along the Sagami trough, Japan.
\end{abstract}

Keywords: Global navigation satellite system, Transient, Boso slow slip event, Kanto earthquake

\section{Introduction}

Numerous slow slip events (SSEs) have been revealed by geodetic networks such as the global navigation satellite system (GNSS) in subduction zones worldwide (Schwartz and Rokosky 2007). The discovered SSEs mainly occur in the transition area between a seismogenic zone and an aseismic creeping area of the subduction interface with an approximate recurrence interval (Schwartz and Rokosky 2007).

Since the mechanism of SSEs is still not well understood, investigation of SSEs is important to obtain insight into the physical processes on the subduction interface. Monitoring of SSEs is also indispensable to assess the hazard potential of nearby areas since some SSEs lead to large thrust earthquakes on the subduction interface (e.g., Radiguet et al. 2016). Furthermore, numerical simulation suggests that a change in the recurrence interval of SSEs occurs when a nearby large fault nears failure because of the buildup of stress at the bottom of the locked zone

*Correspondence: ozawa-s96sa@mlit.go.jp

Geospatial Information Authority of Japan, Tsukuba, Ibaraki 305, Japan
(Matsuzawa et al. 2010). With this background, it was pointed out that the recurrence interval of the Boso SSEs in Japan evolved in a complicated manner from 1996 to 2014, spanning the 2011 Tohoku earthquake (e.g., Ozawa 2014). The Boso SSEs are suitable for investigating the evolution of an SSE cycle perturbed by a great earthquake. Furthermore, there is a possibility that the change in the slow slip cycle of Boso SSEs is associated with the nearby Kanto earthquake cycle, which is important from the viewpoint of hazard assessment.

Boso peninsula is located in the Kanto region, east Japan, as shown in Fig. 1. The Philippine Sea plate subducts from the Sagami trough in the northwest direction beneath the Okhotsk plate at an annual rate of $5 \mathrm{~cm} /$ year, with the Pacific plate subducting westward from the Japan trench at a rate of $9 \mathrm{~cm} /$ year beneath the Okhotsk plate (e.g., Kreemer et al. 2014) (Fig. 1a). Since it has been pointed out that the Kanto region belongs to a different block from the Okhotsk plate, we hereafter use the term CJP as the 'central Japan block' instead of the Okhotsk plate (Nishimura et al. 2007). Because of the subduction of the Philippine Sea plate, Kanto earthquakes 


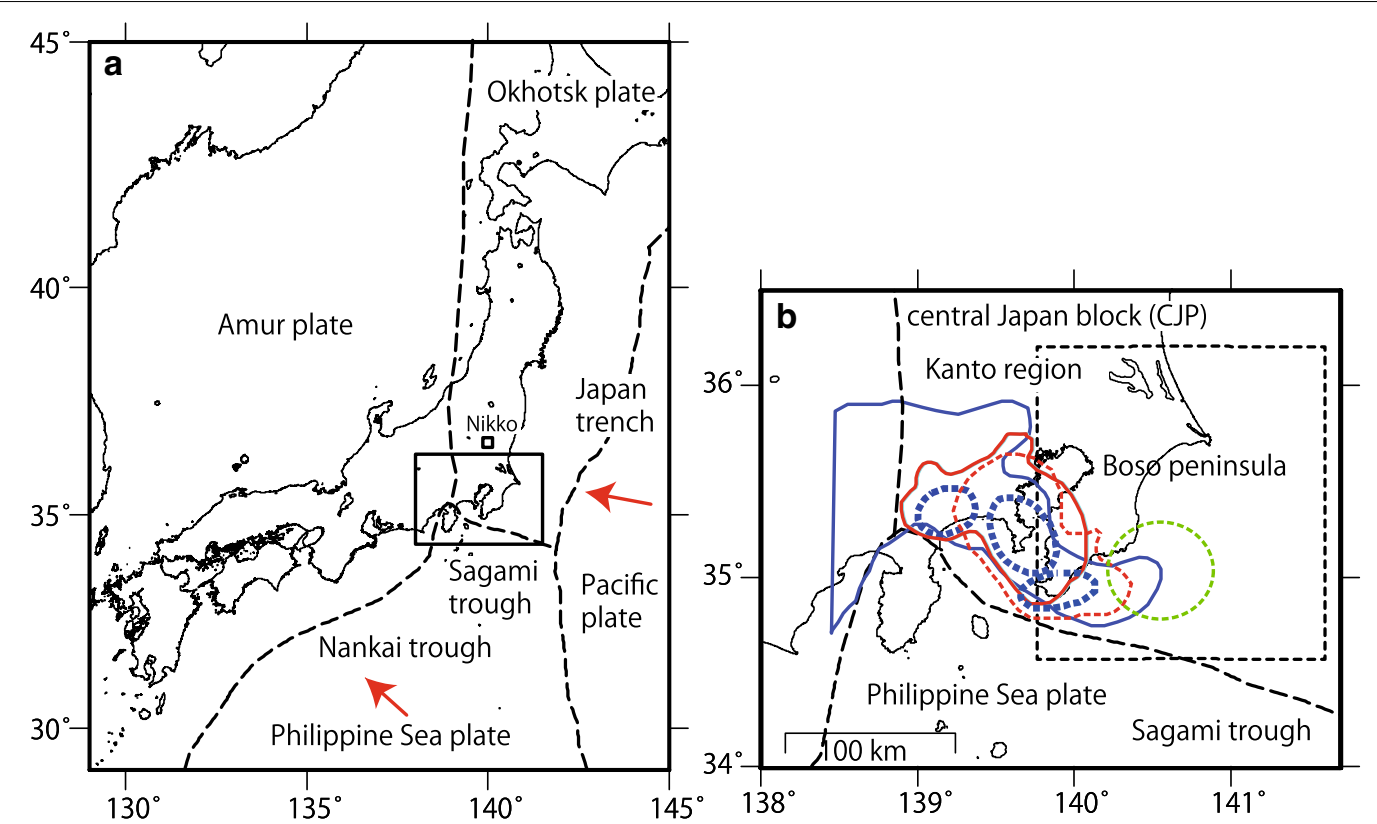

Fig. 1 a Tectonic setting in and around Japan. Broken lines indicate plate boundaries. Four major plates are converging in Japan. $\mathbf{b}$ Enlarged map of the Boso peninsula indicated by the rectangle in $\mathbf{a}$. Broken lines indicate plate boundaries. The broken red line indicates the source area of the 1703 Genroku earthquake (Sato et al. 2016), while the solid red line indicates the source area of the 1923 Taisho Kanto earthquake (Matsu'ura et al. 2007). The blue line indicates the coupled area estimated by Noda et al. (2013) on the basis of GNSS data. The blue broken lines indicate the three asperities assumed by Sato et al. (2016). The black broken rectangle shows the fault patch used to estimate the aseismic slip on the plate interface between the Philippine Sea plate and the continental plate (see text). The green broken line schematically shows the Boso slow slip area, which lies in the transition zone between a locked area and an aseismic creeping area. The central Japan block is explained in the text

have repeatedly occurred on the strongly coupled interface between the CJP and the Philippine Sea plate. The Kanto region has two major modes of earthquakes. One is exemplified by the 1923 Taisho Kanto earthquake [moment magnitude $\left(M_{w}\right)$ 8.2] and the other by the 1703 Genroku Kanto earthquake $\left(M_{w}\right.$ 8.2) (Matsuda et al. 1978). Sato et al. (2016) estimated the recurrence interval of any type of the Kanto earthquake to be 350 years and 1400 years for the Genroku-type earthquake from paleoshoreline data. Figure $1 \mathrm{~b}$ shows the source areas of these two types of Kanto earthquake estimated by Matsu'ura et al. (2007) and Sato et al. (2016). On the basis of these models, Sato et al. (2016) assumed three asperities along the Sagami trough area, which are shown in Fig. 1b. At the time of the 1923 Taisho Kanto earthquake, the northern and central asperities ruptured, whereas the central and southern asperities ruptured as a result of the 1703 Genroku earthquake. It has been suggested that the southernmost asperity may slip independently with a time interval of several 100 years (Komori et al. 2017).

In this complicated tectonic setting, SSEs have occurred repeatedly on the plate interface between the subducting Philippine Sea plate and the overriding CJP off the Boso peninsula, Japan, in the transition area between the shallower locked area (e.g., Noda et al. 2013) and the deeper aseismic creeping area on the plate interface as shown in Fig. 1b. The duration of the Boso SSEs is roughly 1-2 weeks during which significant changes occur. The recurrence interval of the major Boso SSEs was 4-6 years before the 2011 Tohoku earthquake (e.g., Ozawa 2014). Geodetically detected events before the Tohoku earthquake occurred in May 1997, October 2002 and August 2007. A possible tiltmeter change was observed associated with high seismicity in January 1991, which indicated the occurrence of a Boso SSE (e.g., Hirose et al. 2012). Gardonio et al. (2018) suggested the possibility of the occurrence of small Boso SSEs in 2005 and 2010 from repeating earthquakes and geodetic data. SSEs after the Tohoku earthquake occurred in October 2011 and December 2013-January 2014. It has been hypothesized that a Boso SSE occurred immediately after the 2011 Tohoku earthquake from a seismicity study (Kato et al. 2014). Thus, the recurrence interval of the major events shortened from 4 to 6 years before the Tohoku earthquake to 0.6 years between the first and second events immediately after the 2011 Tohoku earthquake and increased from 0.6 to 2.2 years after the October 2011 event.

Under these circumstances, the GNSS network in Japan detected a transient in the Boso peninsula, indicating the 
occurrence of a Boso SSE in June 2018, 4.4 years after the previous 2014 event. In this study, we estimate the spatiotemporal evolution of the latest Boso SSE and compare it with the preceding events and discuss the change in the recurrence interval and its implications.

\section{Methods}

GNSS data were analyzed using Bernese software (version 5.0) on a daily basis with precise ephemeris and earth rotation parameters (Ozawa et al. 2012). We transformed coordinates of longitudes, latitudes and heights to east-west, north-south and up-down components in a local framework. After this transformation, we estimated the linear trend and the annual and semiannual periodic components for the period between 1996 and 2011 before the 2011 Tohoku earthquake and removed them from position time series for the entire period (Additional file 1). We also removed postseismic deformation after the Tohoku earthquake using logarithm and exponential functions (Additional file 1).

We modified the time-dependent inversion (McGuire and Segall 2003) (Additional file 1) slightly and applied it to the east-west, north-south and up-down components at 49 selected GNSS sites (see Fig. 2e) for the period of the 2018, 2013-2014, October 2011, 2007, 2002 and 1996 events (see Table 1). We did not analyze the smaller events and the March 2011 event, since there are no clear signals in the position time series for the corresponding period. We weighted the horizontal and vertical components in the ratio of 5:1 in the following analysis, considering day-to-day scatter. We evaluated the effect of this weighting and confirmed that it did not change the results significantly.

In the time-dependent inversion, we used a parametric spline surface to represent a fault interface and a slip distribution on a fault (Ozawa et al. 2012). We adopted the geometric model of the Philippine Sea plate proposed by Hirose et al. (2008). The spatial extent of the adopted plate interface model for calculation is shown in Fig. 1b. We took 11 grids in the NS direction and 12 grids in the EW direction in Fig. 1b. The spacing of the grids in both directions is approximately $15 \mathrm{~km}$.

We constrained the aseismic slip vector on the plate surface to within $20^{\circ}$ from the opposite direction of the motion of the Philippine Sea plate against the CJP. The direction of the motion of the Philippine Sea plate against the CJP is from Nishimura et al. (2007). Our algorithm well reproduces the synthetic slip based on the synthetic data (Additional file 1: Figure S1).

\section{Results and discussion}

Figure 2 shows detrended time series at selected GNSS sites relative to the Nikko site (Fig. 1a) in 2018. The standard deviation in Fig. $2 \mathrm{a}-\mathrm{d}$ was estimated from the

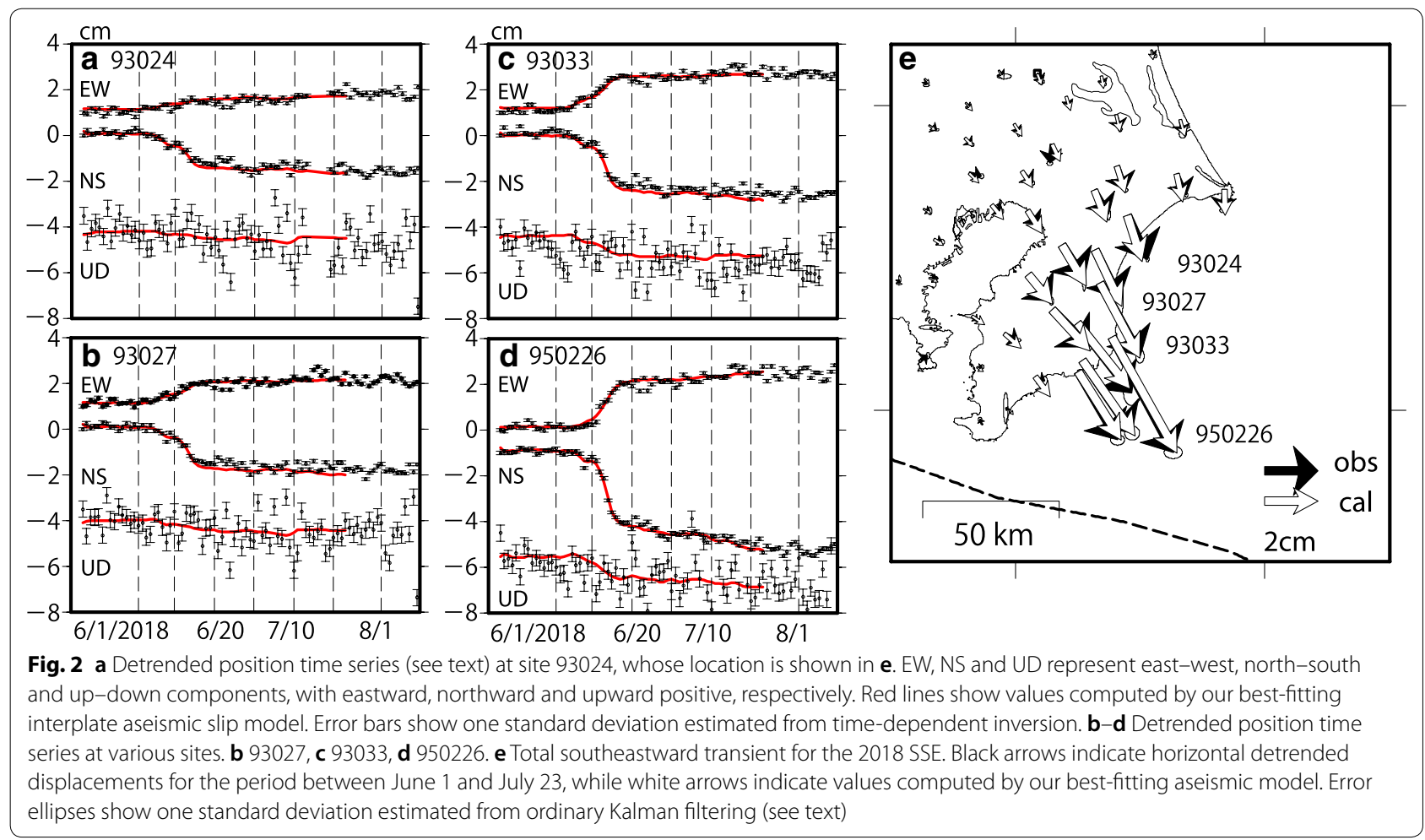


Table 1 Moment, maximum slip and maximum slip rate of Boso SSEs. Data of the 2005 and 2010 events are from Gardonio et al. (2018)

\begin{tabular}{|c|c|c|c|c|c|}
\hline SSE & Moment $\left(10^{18} \mathrm{~N} \mathrm{~m}\right)$ & $M_{w}$ & Duration for total moment & Maximum slip (cm) & $\begin{array}{l}\text { Maximum slip } \\
\text { rate }(\mathrm{cm} / \text { day })\end{array}$ \\
\hline 2018 & $19.5 \pm 2.0$ & 6.8 & $6 / 1 / 2018-7 / 23 / 2018$ & 21 & 2.8 \\
\hline 2014 & $6.6 \pm 1.0$ & 6.5 & $12 / 23 / 2013-1 / 30 / 2014$ & 9 & 1.1 \\
\hline October 2011 & $12.5 \pm 1.5$ & 6.7 & 10/12/2011-12/10/2011 & 17 & 2.5 \\
\hline March 2011 & $?$ & $?$ & March 2011 & & \\
\hline 2010 & 1.8 & 6.1 & March 2010 & & \\
\hline 2007 & $10.8 \pm 1.2$ & 6.6 & 8/3/2007-9/7/2007 & 14 & 1.5 \\
\hline 2005 & 1.0 & 5.8 & March 2005 & & \\
\hline 2002 & $12.3 \pm 1.6$ & 6.7 & $9 / 23 / 2002-11 / 30 / 2002$ & 16 & 1.4 \\
\hline 1996 & $8.7 \pm 1.1$ & 6.6 & 5/7/1996-6/24/1996 & 9 & 1.1 \\
\hline
\end{tabular}

? means unknown

time-dependent inversion. As, respectively, shown in Fig. 2a-d, southeastward transients at 93024, 93027, 93033 and 950226 in the Boso peninsula were observed from early June 2018. Interestingly, the start of the southeastward transient seems to become delayed from 93024 to 950226 . We applied ordinary Kalman filtering to each position time series and estimated the trend and autoregressive components and their standard deviation (Kitagawa and Gersch 1996). Figure 2e shows the estimated trend or displacement and its standard deviation for the period between June 1 and July 23, 2018. We can see southeastward movements, with site 950226 showing the largest displacement of approximately $6 \mathrm{~cm}$. This southeastward transient is opposite to the inter-SSE movements and suggests SSEs in this region on the plate interface. Additional file 1: Figure S2 shows the resulting transients for the last five major events, clearly showing the initiation and cessation of each event.

The results of the time-dependent inversion of the 2018 event show the initial slow slip off site 950226 in the central Boso peninsula from June 4, 2018 (see Fig. 3b). The center of the slip area moved south over time. From June 4-6 to June 6-8, the slip area expanded, while the slip rate decreased from June 6-8 to near the limit of the detection level on June 8-10. Such a decrease in the slip rate during the period of slip acceleration has not been observed in the past Boso SSEs. The maximum slip rate per 2 days increased to $2 \mathrm{~cm}$ from June 10 to 12 with the expansion of the slip area. The slip rate per 2 days sharply increased to a maximum of $5 \mathrm{~cm}$ from June 12 to 14 and a maximum of $4 \mathrm{~cm}$ from June 14 to 16 with the expansion of the slip area. The slip rate rapidly decayed over time after June 16 with the slip area shrinking rapidly. Considering the uncertainties, we cannot clearly give the exact date for the cessation of aseismic slip. We chose the end dates of Fig. 3 and Additional file 1: Figure S3 when slip rate becomes roughly less than $1 \mathrm{~cm} / 2$ days.
The estimated southward shift of the slip center over time was also observed in the previous events (Additional file 1: Figure S3). The uncertainties in Fig. 3 are shown in Additional file 1: Figure S4. The earthquakes within $5 \mathrm{~km}$ from the plate interface associated with the slow slip occurred off the central Boso peninsula from June 4, 2018, and expanded to the south along the eastern coast of the Boso peninsula, as was observed in the previous cases. We cannot clearly state whether the seismic swarm or slow slip came first, although we can see earthquakes from July 2 to 4.

Figure 4 shows a comparison of the estimated total slip in the Boso SSEs. We estimated the total slip for the period from shortly before the initiation to shortly after the cessation of transient deformation which contains small gradual signals following the significant changes of 1-2 weeks. As shown here, the location of the rupture area is almost the same among all events off the southeast of the Boso peninsula. The slip of over $4 \mathrm{~cm}$ in Fig. 4 is larger than the standard deviation in Additional file 1: Figure S5. The earthquakes within $5 \mathrm{~km}$ from the plate interface are distributed along the landward or downdip boundary of the estimated slip area in all cases. Many SSEs in other subduction zones are associated with seismic tremors and not ordinary earthquakes (e.g., Schwartz and Rokosky 2007). The depths of the Boso SSEs are less than those of many other SSEs in the world (e.g., Schwartz and Rokosky 2007). The shallowness of the SSEs may be the reason for the strong relationship with the microseismicity, considering the shallow SSEs in New Zealand, which are similar to Boso SSEs in depth, duration, magnitude, and their relationship with the microseismicity (Bartlow et al. 2014).

The moment of the 2018 event is $20 \times 10^{18} \mathrm{~N}$ m with a rigidity of $30 \mathrm{GPa}$ (Fig. $4 \mathrm{~g}$ and Table 1 ). The maximum slip and slip rate of the 2018 event are $21 \mathrm{~cm}$ and $2.8 \mathrm{~cm} /$ day (see Figs. 3, 4), respectively, which are the largest 

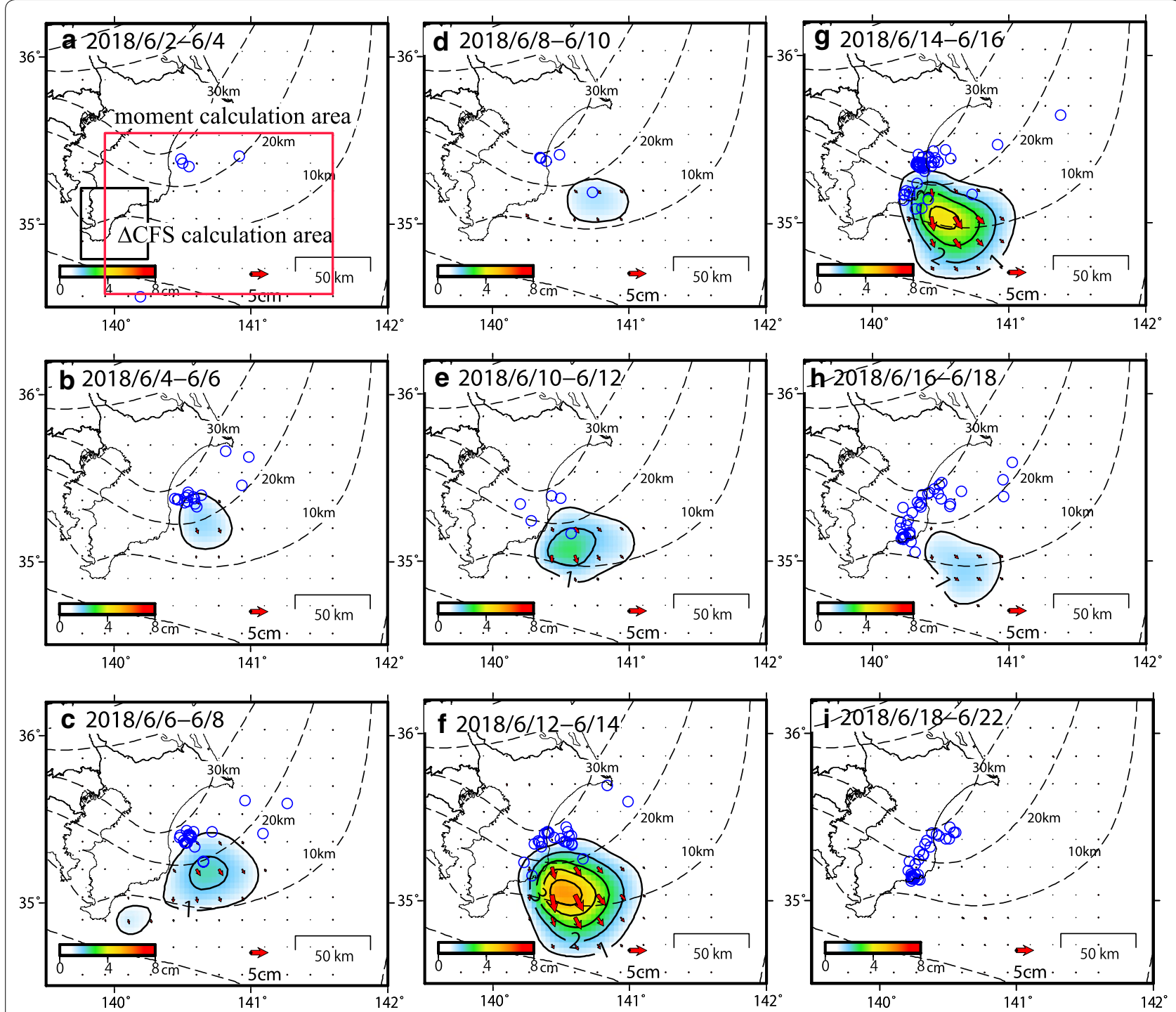

Fig. 3 a Estimated aseismic slip per 2 days on the interface between the CJP and the Philippine Sea plate for the period between June 2, 2018, and June 4, 2018, with a contour interval of $1 \mathrm{~cm} / 2$ days. The color shows the magnitude of slippage, while the arrows show slip vectors. The dashed lines indicate isodepth contours of the plate interface with an interval of $10 \mathrm{~km}$. Blue circles indicate the hypocenters of earthquakes within $5 \mathrm{~km}$ from the plate interface for the corresponding period. The black rectangle shows the area where $\triangle C F S$ is calculated. The red rectangle shows the area of the moment calculation. b-i Estimated aseismic slip for various periods. b June 4, 2018-June 6, 2018. c June 6, 2018-June 8, 2018. d June 8, 2018-June 10, 2018. e June 10, 2018-June 12, 2018. f June 12, 2018-June 14, 2018. g June 14, 2018-June 16, 2018. h June 16, 2018-June 18, 2018. i June 18, 2018-June 22, 2018

among the Boso SSEs, as shown in Fig. 4 and Table 1. This large increase in the moment after a large earthquake has also been observed for the SSEs in Costa Rica (Voss et al. 2017). It remains unknown the reason why the 2018 event is larger than the 2011 and 2014 events. The peak slip rate of the Boso SSEs is large compared with those of other subduction SSEs (Bartlow et al. 2014).

Our models well reproduce the observations (see Fig. 2 and Additional file 1: Figure S2). Our results are basically consistent with the previous studies, despite several analytical differences, in that the main slip area is southeast of the Boso peninsula and that southward or southeastward updip propagation of the slip area is observed, although there are slight differences in the time evolution of slip propagation in some cases (Fukuda 2018; Hirose et al. 2014).

In the following discussion, we treat major events with $M_{w} \geq 6.5$, since small events with $M_{w} \leq 6.1$ are insignificant in the energy balance. We assume that the March 2011 event was a major event with $M_{w} \geq 6.5$. The 

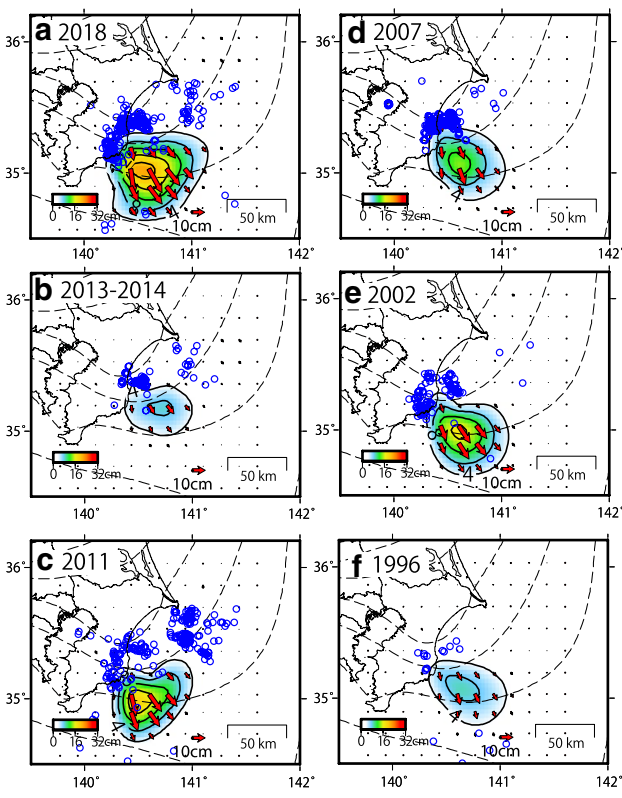

9

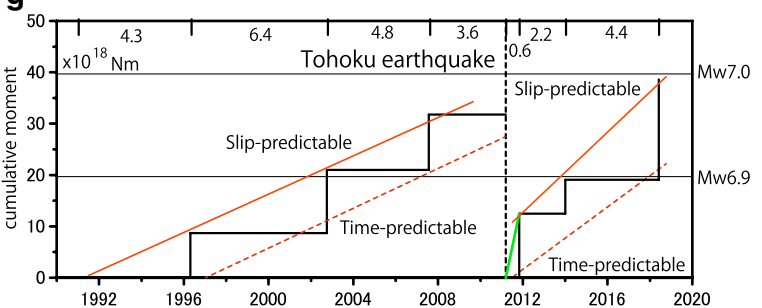

Fig. 4 a Estimated interplate slip for the period between June 1, 2018 and July 23, 2018. The contour interval is $4 \mathrm{~cm}$. Blue circles indicate the hypocenters of earthquakes within $5 \mathrm{~km}$ from the plate interface for the corresponding period. The nomenclature is the same as that in Fig. 3. b December 23, 2013-January 30, 2014. c October 12, 2011-December 10, 2011. d August 3, 2007-September 7, 2007 e September 23, 2002-November 30, 2002. f May 7, 1996-June 24, 1996. $\mathbf{g}$ Cumulative moment and recovery of the recurrence interval. The red solid line shows the slip-predictable model line while the red broken line shows the time-predictable model line before and after the Tohoku earthquake (see text). The green line is the slip-predictable line between March 2011 and October 2011, whose slope appears to be high compared with that after the October 2011 event (see text)

recurrence interval of the major Boso SSEs with $M_{w} \geq 6.5$ is shown in Fig. 4g. The recurrence interval before the Tohoku earthquake ranged from 4 to 6 years. After the 2011 Tohoku earthquake, the recurrence interval was shortened to 0.6 years, and then it increased to 2.2 and 4.4 years. Thus, we consider that the recurrence interval of major events recovered to the pre-Tohoku earthquake value 7 years after the Tohoku earthquake. If we do not take into account the March 2011 event, the recurrence interval was shortened to 2.2 years, then increased to 4.4 years after the Tohoku earthquake. The recurrence interval of the SSEs in Costa Rica did not change after the $M_{w} 7.0$ subduction earthquake nearby, although the spatial distribution of the slip of the first SSE after the earthquake was affected (Voss et al. 2017). Thus, more case studies are necessary to understand the effect of the perturbation of a large earthquake on the SSE cycle.

We calculated the Coulomb failure stress change $(\triangle \mathrm{CFS})$ caused by the 2011 Tohoku earthquake for the CJP moving in the direction opposite to the motion of the Philippine Sea plate with a friction coefficient of 0.2. We used the model of the Tohoku earthquake proposed by Ozawa et al. (2012). The computed $\triangle$ CFS increased by up to $20 \mathrm{kPa}$ in the main slip area of the Boso slip, although some of the main slip area showed a slightly negative $\triangle$ CFS (Additional file 1: Figure S6). Stress modulation by Earth's tides is one order smaller or the same order as the above $\triangle \mathrm{CFS}$. This result is roughly consistent with the computation in the main slow slip area by Hirose et al. (2012). We cannot rule out the possibility that the Boso SSE immediately after the Tohoku earthquake may have been due to the stress change caused by the Tohoku earthquake. The afterslip model of Ozawa et al. (2012) near the Kanto region increases $\triangle$ CFS, suggesting one possible cause of the short interval between the March and October 2011 events (Additional file 1: Figure S7). Shortening of the recurrence interval or repetition of SSEs as earthquake failure nears, which has been suggested by numerical simulation (Matsuzawa et al. 2010), does not apply to the situation of the Boso SSEs, which was evidenced by the 2018 event.

We showed the relationship between the cumulative moment of the major Boso SSEs and the time lapse in Fig. 4g. Since the event immediately after the Tohoku earthquake was not detected geodetically, its magnitude is unknown. We separated the data before and after the Tohoku earthquake, since the cumulative moment trend is clearly different before and after the Tohoku earthquake. We then showed the slip-predictable model line and time-predictable model line before and after the 2011 Tohoku earthquake in Fig. 4g.

In the slip-predictable model, strain energy accumulated above some threshold is released when rupture occurs, while fault rupture occurs when the accumulated strain energy reaches some threshold in the time-predictable model (Shimazaki and Nakata 1980) (see Additional file 1: Figure S8). We regressed linear functions to the cumulative moment data based on the slip-predictable and time-predictable models. The estimated slope of the slip-predictable model is $1.9 \pm 0.1 \times 10^{18} \mathrm{~N} \mathrm{~m} /$ year with a log-likelihood of -2.6 , while that of the timepredicted model is $1.9 \pm 0.2 \times 10^{18} \mathrm{~N} \mathrm{~m}$ /year with a loglikelihood of -7.1 before the Tohoku earthquake. Thus, Fig. 4g indicates a slip-predicable model rather than 
a time-predictable model based on the log-likelihood before the Tohoku earthquake. With regard to the events after the earthquake, the moment of the October 2011 event is very large, and the slip-predictable slope (green line in Fig. 4g) between March and November 2011 is clearly different from that after the October 2011 event. If we exclude the March 2011 event, the slope of the slippredictable model is $3.9 \pm 0.2 \times 10^{18} \mathrm{~N} \mathrm{~m}$ /year with a $\log$-likelihood of -1.5 , while that of the time-predictable model is $3.0 \pm 0.6 \times 10^{18} \mathrm{~N} \mathrm{~m}$ /year with a log-likelihood of -5.6 after the Tohoku earthquake. There is a possibility that subduction of the Philippine Sea plate accelerated after the Tohoku earthquake in the Kanto region according to a study on repeating earthquakes (Uchida et al. 2016). If the velocity of the plate subduction rapidly increased immediately after the earthquake and then slightly decreased, the rapid increase in the moment release rate for 0.6 years and the slight decrease after that in the slip-predictable model may be explained together with the change in $\triangle \mathrm{CFS}$ by the afterslip of the Tohoku earthquake (Additional file 1: Figure S7). This acceleration of the subduction of the Philippine Sea plate may also result in the considerable increase in the moment after the Tohoku earthquake. Because of the scarcity of data, we could not find a suitable relaxation function for use as a slip-predictable model after the Tohoku earthquake. The next Boso SSE may provide us with more information on this hypothesis.

To assess the effect of the Boso SSEs on the nearby asperity, we calculated $\triangle \mathrm{CFS}$ near the strongly coupled area off the southern tip of the Boso peninsula (see Fig. 3a) from the cumulative slip of the Boso SSEs from 1996 to 2018. We did not incorporate the 2005 and 2010 events, which have not been well resolved geodetically. The slip direction and friction coefficient in the $\triangle \mathrm{CFS}$ calculation were the same as those used in the $\triangle \mathrm{CFS}$ calculation for the 2011 Tohoku earthquake model. We set slips of less than $1 \mathrm{~cm}$ equal to zero. The result shows an increase in $\triangle C F S$ of $10-100 \mathrm{kPa}$ on the plate interface between the Philippine Sea plate and the CJP from 1996 to 2018 (Additional file 1: Figure S9). Thus, the Boso SSEs changed the stress state in favor of a large interplate earthquake in the region of the southernmost asperity off the Boso peninsula. $\triangle$ CFS for the 2011 Tohoku earthquake is slightly negative and negligible in this region.

\section{Conclusion}

In this study, we showed the spatiotemporal evolution of the slip distribution of the 2018 Boso SSE, which evolved similarly to the previous Boso SSEs. The 2011 Tohoku earthquake did not significantly change the spatiotemporal distribution of the slip in the case of the Boso SSEs, although the recurrence interval seems to have been affected. However, the total moment of the 2018 event is the largest, with the largest slip and slip rate, among the Boso SSEs. The considerable increase in the moment after the Tohoku earthquake may be related to the acceleration of the subduction of the Philippine Sea plate. The increase in the recurrence interval after the Tohoku earthquake, evidenced by the 2018 event, may provide insight into the interaction between an SSE and a great subduction earthquake. Although the 2018 event allows us to reject the hypothesis of shortening of the recurrence interval, the Boso SSEs are changing the stress state in favor of the occurrence of an interplate earthquake along the Sagami trough.

\section{Additional file}

Additional file 1. Additional Figures

\section{Abbreviations}

GNSS: Global navigation satellite system; CJP: central Japan block; SSE: slow slip event; $M_{w}$ : moment magnitude; $\triangle C F S$ : change in Coulomb failure stress.

\section{Acknowledgements}

We would like to acknowledge the Japan Meteorological Agency for providing the hypocenter data of earthquakes.

\section{Authors' contributions}

$\mathrm{SO}, \mathrm{HY}$ and TK analyzed the data and wrote the manuscript. All authors read and approved the final manuscript.

Funding

This research is funded by the Geospatial Information Authority of Japan.

Availability of data and materials

The data used in this paper are available by contacting ozawa-s96sa@mlit. go.jp.

\section{Competing interests}

The authors declare that they have no competing interests.

Received: 14 February 2019 Accepted: 9 July 2019

Published online: 19 July 2019

\footnotetext{
References

Bartlow NM, Wallace LM, Beavan RJ, Bannister S, Segall P (2014) Time-dependent modeling of slow slip events and associated seismicity and tremor at the Hikurangi subduction zone, New Zealand. J Geophys Res 119:734753. https://doi.org/10.1002/2013JB010609

Fukuda J (2018) Variability of the space-time evolution of slow slip events off the Boso peninsula, central Japan, from 1996 to 2014. J Geophys Res 123:732-760. https://doi.org/10.1002/2017JB014709

Gardonio B, Marsan D, Socquet A, Bouchon M, Jara J, Sun Q, Cotte N, Campillo M (2018) Revisiting slow slip events occurrence in Boso peninsula, Japan, combining GPS data and repeating earthquakes analysis. J Geophys Res 123:1502-1515. https://doi.org/10.1002/2017JB014469

Hirose F, Nakajima J, Hasegawa A (2008) Three-dimensional seismic velocity structure and configuration of the Philippine Sea slab in southwest Japan estimated by double-difference tomography. J Geophys Res 113:19782012. https://doi.org/10.1029/2007JB005274
} 
Hirose H, Kimura H, Enescu B, Aoi S (2012) Recurrent slow slip event likely hastened by the 2011 Tohoku earthquake. Proc Natl Acad Sci USA 109(38):15157-15161

Hirose H, Matsuzata T, Kimura T, Kimura H (2014) The Boso slow slip events in 2007 and 2011 as a driving process for the accompanying earthquake swarm. Geophys Res Lett 41:2778-2785. https://doi.org/10.1002/2014G L059791

Kato A, Igarashi T, Obara K (2014) Detection of a hidden Boso slow slip event immediately after the 2011 Mw 9.0 Tohoku-Oki earthquake, Japan. Geophys Res Lett 41:5868-5874. https://doi.org/10.1002/2014GL061053

Kitagawa G, Gersch W (1996) Smoothness priors analysis of time series, Lecture Notes in Statistics. Springer, New York

Komori J, Shishikura M, Ando R, Yokoyama Y, Miyairi Y (2017) History of the great Kanto earthquakes inferred from the ages of Holocene marine terraces revealed by a comprehensive drilling survey. Earth Planet Sci Lett 471:74-84. https://doi.org/10.1016/j.epsl.2017.04.044

Kreemer C, Blewitt G, Klein EC (2014) A geodetic plate motion and global strain rate model. Geochem Geophys Geosyst 15:3849-3889. https://doi. org/10.1002/2014/GC005407

Matsu'ura M, Noda A, Fukahata Y (2007) Geodetic data inversion based on Bayesian formulation with direct and indirect prior information. Geophys J Int 171(3):1342-1351

Matsuda T, Ota Y, Ando M, Yonekura N (1978) Fault mechanism and recurrence time of major earthquakes in southern Kanto district, Japan, as deduced from coastal terrace data. Geol Soc Am Bull 89:1610-1618

Matsuzawa T, Hirose H, Shibazaki B, Obara K (2010) Modeling short- and long-term slow slip events in the seismic cycle of large subduction earthquakes. J Geophys Res 115:B12301. https://doi.org/10.1029/2010J B007566

McGuire JJ, Segall P (2003) Imaging of aseismic slip transients recorded by dense geodetic networks. Geophys J Int 155:778-788

Nishimura T, Sagiya T, Stein RS (2007) Crustal block kinematics and seismic potential of the northernmost Philippine Sea plate and Izu microplate, central Japan, inferred from GPS and leveling data. J Geophys Res 112:B05414. https://doi.org/10.1029/2005JB004102
Noda A, Hashimoto C, Fukahata Y, Matsu'ura M (2013) Interseismic GPS strain data inversion to estimate slip-deficit rates at plate interfaces: application to the Kanto region, central Japan. Geophys J Int 193:61-77. https://doi. org/10.1093/gji/ggs129

Ozawa S (2014) Shortening of recurrence interval of Boso slow slip events in Japan. Geophys Res Lett 41:2762-2768. https://doi.org/10.1002/2014G L060072

Ozawa S, Nishimura T, Munekane H, Suito H, Kobayashi T, Tobita M, Imakiire T (2012) Preceding, coseismic and post seismic slips of the 2011 Tohoku earthquake, Japan. J Geophys Res 117:B07404. https://doi. org/10.1029/2011/JB009120

Radiguet M, Perfettini H, Cotte N, Gualandi A, Valette B, Kostoglodov V, Lhomme T, Walpersdorf A, Cano EC, Campillo M (2016) Triggering of the 2014 Mw7.3 Papanoa earthquake by a slow slip event in Guerrero, Mexico. Nat Geosci 9:829-833. https://doi.org/10.1038/NGEO2817

Sato T, Higuchi H, Miyauchi T, Endo K, Tsumura N, Ito T, Noda A, Matsu'ura M (2016) The source model and recurrence interval of Genroku-type Kanto earthquakes estimated from paleo-shoreline data. Earth Planets Space 68:17. https://doi.org/10.1186/s40623-016-0395-3

Schwartz S, Rokosky JM (2007) Slow slip events and seismic tremor at circum-Pacific subduction zones. Rev Geophys 45:RG3004. https://doi. org/10.1029/2006rg000208

Shimazaki K, Nakata T (1980) Time-predictable recurrence model for large earthquakes. Geophys Res Lett 7:279-282

Uchida N, Asano Y, Hasegawa A (2016) Acceleration of regional plate subduction beneath Kanto, Japan, after the 2011 Tohoku-oki earthquake. Geophys Res Lett 43:9002-9008. https://doi.org/10.1002/2016GL070298

Voss NK, Malservisi R, Dixon TH, Protti M (2017) Slow slip events in the early part of the earthquake cycle. J Geophys Res 122:6773-6786. https://doi. org/10.1002/2016JB013741

\section{Publisher's Note}

Springer Nature remains neutral with regard to jurisdictional claims in published maps and institutional affiliations.

\section{Submit your manuscript to a SpringerOpen ${ }^{\odot}$ journal and benefit from:}

- Convenient online submission

- Rigorous peer review

- Open access: articles freely available online

- High visibility within the field

- Retaining the copyright to your article

Submit your next manuscript at $\boldsymbol{\nabla}$ springeropen.com 